\title{
Incident of Thyroid Carcinomas and Other Pathologies with Age Correlation in Patients Presented with Palpable Thyroid Masses Undergoing Thyroidectomies
}

\author{
Mahwish Niaz', Saba Aneeqa ${ }^{2}$, Faiza Kazi ${ }^{3}$, Mumtaz Ahmad ${ }^{4}$, Hassan Salim5, Iram Sohail ${ }^{6}$
}

Consultant Pathologist, Foundation University Medical College, Islamabad Pakistan

1 Conception of designing of work

2 Demonstrator, Department of Pathology, Foundation University Medical College, Islamabad Pakistan

2 Conception of designing of work

3 Professor, Department of Pathology, Foundation University Medical College, Islamabad Pakistan Work design and revision of concept

4 Professor, Department of Pathology, Fauji Foundation Hospital, Islamabad Pakistan

4 Final Approval of version

5 Senior Registrar, Department of Medicine, Foundation University Medical College, Islamabad Pakistan

5 Drafting of work

6 Consultant Pathologist, Department of Pathology, Foundation University Medical College, Islamabad Pakistan

6 Drafting of work

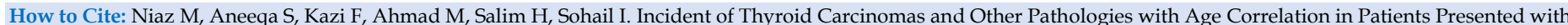
Palpable Thyroid Masses Undergoing Thyroidectomies. APMC 2021;15(1):84-8. DOI: 10.29054/APMC/2021.733
CORRESPONDING AUTHOR

Dr. Mahwish Niaz

Consultant Pathologist, Foundation University

Medical College, Islamabad Pakistan

Email:mahwishhassan83@gmail.com

Submitted for Publication: 25-10-2019 Accepted for Publication 17-02-2021

\section{ABSTRACT}

Background: Thyroid cancer is the leading cause of death both in developing and developed countries. Patients present with enlarged thyroid. Radiology shows hot and cold nodules. Thyroidectomy or lobectomy is done to rule out malignancy. Objective: To determine the incidence of thyroid carcinomas and other pathologies in thyroidectomy specimen of different age group patients presenting with clinically enlarged thyroid. Study Design: This was a cross-sectional study. Settings: conducted in the Department of Histopathology, Foundation University Medical College (FUMC), Islamabad and Department of surgery, Fauji Foundation Hospital (FFH), Rawalpindi Pakistan. Duration: from Jan 2012 to March 2019. Methodology: All the thyroidectomies specimens send from Surgery department of FFH to Histopathology Department of FUMC during study period and fulfilling the pre-set criteria were included in the study. All the data and results were analyzed using SPSS version 17.0. Results: Out of 500 total patients, $89 \%(n=445)$ were diagnosed as having multinodular goiter, 2.6\% $(n=13)$ thyroiditis, 2.2\% ( $n=11)$ follicular adenoma, $0.8 \%(n=4)$ Hurthle cell adenoma, $0.2 \%(n=1)$ hyalinizing trabacular adenoma and thyroid carcinomas. The carcinomas comprised $2.6 \%(\mathrm{n}=13)$ papillary carcinoma, $0.8 \%(\mathrm{n}=4)$ poorly differentiated carcinoma, $0.8 \%(n=4)$ anaplastic carcinoma, $0.6 \%(n=3)$ medullary carcinoma and $0.4 \%(n=2)$ follicular carcinoma. In 445 patients of multinodular goiter 158 patients were in the age range of $41-50$ years, in 13 cases of thyroiditis 7 were in the age range of 31-40 years, in 11 cases of follicular adenoma 4 patients were in the age range of 31-40 years, in 4 cases of hurthle cell adenoma 3 patients were in the age range of 41-50 years, in 13 cases of papillary thyroid carcinoma 5 patients were in the age range of 31-40 years, in 4 cases of poorly differentiated carcinoma 2 patients were in the age range of 41-50 years and in 4 cases of anaplastic carcinoma 2 patients were in the age range of 61-70 years. Conclusion: The study concluded that thyroid carcinomas collectively constituted $5.20 \%$ of the study cases. Papillary carcinoma was the most frequent malignant neoplasm constituting $2.6 \%$ and occurring mostly in the age range of 31-40 years, while anaplastic carcinoma comprised of $0.8 \%$ of malignant lesions occurring in the age range of $61-70$ years. The most frequent cause of thyroid enlargement was multinodular goiter (89\%) with majority of the patients in the age range of $41-50$ years.

Keywords: Thyroid swelling, Thyroid Carcinoma, Thyroiditis, Adenoma and Multinodular goiter.

\section{INTRODUCTION}

Thyroid disease is common not only in Pakistan but also all over the world. ${ }^{1}$ Factors associated with increased incidence depend upon iodine status, but also on advancing age, gender, ethnical group and geographical area. $^{2,3}$ Its rising incidence is also associated with highest mortality rate annually as compared to all other endocrine cancers. ${ }^{4}$ Thyroid cancer is considered $16^{\text {th }}$ most prevalent cancer globally that affect both developed and underdeveloped countries equally. ${ }^{5}$ In Pakistan the overall incidence of thyroid carcinoma is $1.2 \%$ with papillary thyroid carcinoma comprising 69-71\%, follicular thyroid carcinoma 11-13\%, medullary thyroid carcinoma $3-5 \%$ and anaplastic thyroid carcinoma $1-2 \% .6$ The exact diagnosis of thyroid lesion requires histopathology on thyroidectomy specimens ${ }^{7}$. Different modalities are employed for early detection of the lesions such as Ultrasound, thyroid scan and Fine Needle 
Aspiration Cytology. ${ }^{7}$ Recommendations are that all thyroid nodules greater than $1 \mathrm{~cm}$ in size must be evaluated thoroughly to rule out malignancy. ${ }^{8}$ Among general population, most of these nodules are benign and only $5-25 \%$ represents thyroid cancer. ${ }^{9}$ The various thyroid carcinomas derived from thyroid follicular epithelium include papillary carcinoma, follicular carcinoma, poorly differentiated carcinomas and anaplastic carcinoma, while medullary carcinoma arises from parafollicular / C cells.4,10 Follicular carcinoma shows vascular and capsular invasion due to which it is differentiated from follicular adenoma. Papillary thyroid carcinoma is a malignant tumor forming papillary and follicular structures. It has characteristic nuclear changes such as overlapping, crowding, grooving and clearing. It spreads via lymphatics to cervical lymph nodes. Medullary carcinoma can be familial or sporadic. Microscopically cells are either polygonal or fusiform with well-defined borders, cytoplasm is eosinophilic with occasional granules. A dense amorphous material i.e., amyloid deposition in stroma is a characteristic feature. Anaplastic carcinoma is most aggressive tumor occurring in older age group. Clinically it presents with rapid thyroid enlargement, dyspnea and dysphagia. ${ }^{7}$

The benign non neoplastic conditions include multinodular goiter, various types of thyroiditis including Hashimoto's thyroiditis, de Quervain thyroiditis, lymphocytic thyroiditis and palpation thyroiditis. The thyroid adenomas include follicular adenoma, Hurthle cell adenoma and hyalinizing trabecular adenoma. ${ }^{4}$ Colloid goiter (endemic goiter) is the enlargement of normal thyroid gland. It occurs due to iodine deficient diet especially in iodine deficient areas. ${ }^{7}$ Toxic multinodular goiter (multinodular goiter) is one of the causes of hyperthyroidism, after Grave's disease. ${ }^{6}$ Follicular adenoma is a benign tumor exhibiting follicular differentiation microscopically without vascular and capsular invasion. ${ }^{7}$

The aim of this study was to determine the incidence of thyroid cancer and its correlation with different age groups.

\section{METHODOLOGY}

Study Design: Cross-sectional study.

Settings: This study was conducted in the Department of Histopathology, Foundation University Medical College, Islamabad campus and Department of surgery, Fauji Foundation Hospital, Rawalpindi Pakistan.

Duration: From Jan 2012 to Mar 2019.

Sample Technique: Non-probability consecutive sampling.

Sample Size: 500 patients.

Inclusion Criteria: All properly fixed thyroidectomy specimens of any age and sex.

Exclusion Criteria: Autolyzed and poorly fixed thyroidectomy specimen.

Data Collection Procedure: After approval from Ethical Research Committee (ERC) of FUMC, all the thyroidectomies specimens received in the Histopathology Department during study period and fulfilling the pre-set criteria were included in the study. Patient's data was recorded on predesigned proforma. These specimens were fixed in $10 \%$ neutral buffered formalin followed by grossing, processing and paraffin embedding. The slides were manually stained with Haematoxylin and Eosin by an experienced lab technician. Microscopic evaluation was initially done by the postgraduate trainee and later on confirmed by two consultant histopathologists.

\section{RESULTS}

A total of 500 patients were included according to the inclusion criteria of the study. Frequency of various pathologies in thyroidectomy specimens was analyzed which included $89 \%$ multinodular goiter, $2.6 \%$ thyroiditis, $2.2 \%$ follicular adenoma, $0.8 \%$ Hurthle cell adenoma, $0.2 \%$ hyalinizing trabacular adenoma and thyroid carcinomas including $2.6 \%$ papillary carcinoma, $0.8 \%$ poorly differentiated carcinoma, $0.8 \%$ anaplastic carcinoma, $0.6 \%$ medullary carcinoma and $0.4 \%$ follicular carcinoma as shown in table 1.

Table 1: Frequency and percentage of various thyroid diseases $(n=500)$

\begin{tabular}{|c|c|c|c|c|}
\hline Nature of lesion & Diseases & Frequency of individual lesion & $\begin{array}{c}\text { Percentage }(\%) \\
\text { of individual lesion }\end{array}$ & $\begin{array}{l}\text { Overall Frequency } \\
\text { \& Percentage }\end{array}$ \\
\hline Malignant & $\begin{array}{l}\text { Papillary carcinoma (PTC) } \\
\text { Poorly differentiated carcinoma } \\
\text { Anaplastic carcinoma } \\
\text { Medullary carcinoma (MTC) } \\
\text { Follicular carcinoma (FC) }\end{array}$ & $\begin{array}{c}13 \\
4 \\
4 \\
3 \\
2\end{array}$ & $\begin{array}{l}2.6 \\
0.8 \\
0.8 \\
0.6 \\
0.4\end{array}$ & $\begin{array}{c}26 / 500 \\
5.2 \%\end{array}$ \\
\hline Benign & $\begin{array}{l}\text { Multinodular goiter (MNG) } \\
\text { Thyroiditis } \\
\text { Follicular adenoma (FA) } \\
\text { Hurthle cell adenoma (HCA) } \\
\text { Hyalinizing trabecular tumor (HTT) }\end{array}$ & $\begin{array}{c}445 \\
13 \\
11 \\
4 \\
1\end{array}$ & $\begin{array}{l}89 \\
2.6 \\
2.2 \\
0.8 \\
0.2\end{array}$ & $\begin{array}{c}474 / 500 \\
94.8 \%\end{array}$ \\
\hline & Total & 500 & 100 & \\
\hline
\end{tabular}


Out of 445 patients of multinodular goiter 158 patients were in the age range of 41-50 years, seven of 13 cases of thyroiditis were in the age range of 31-40 years, 4 of 11 cases of follicular adenoma 4 patients were in the age range of 31-40 years, in 4 cases of hurthle cell adenoma 3 patients were in the age range of $41-50$ years, in 13 cases of papillary thyroid carcinoma 5 patients were in the age range of 31-40 years, in 4 cases of poorly differentiated carcinoma 2 patients were in the age range of 41-50 years and in 4 cases of anaplastic carcinoma 2 patients were in the age range of 61-70 years as shown in table 2

Table 2: Age wise distribution of thyroid lesions $(n=500)$

\begin{tabular}{|l|c|c|c|c|c|c|c|c|}
\hline \multicolumn{1}{|c|}{ Histological diagnosis } & $\mathbf{n}$ & Percentage & $\begin{array}{c}\text { Less than } \\
\text { 20 years }\end{array}$ & $\begin{array}{c}\mathbf{2 1 - 3 0} \\
\text { years }\end{array}$ & $\begin{array}{c}\mathbf{3 1 - 4 0} \\
\text { years }\end{array}$ & $\begin{array}{c}\mathbf{4 1 - 5 0} \\
\text { years }\end{array}$ & $\begin{array}{c}\mathbf{5 1 - 6 0} \\
\text { years }\end{array}$ & $\begin{array}{c}\mathbf{6 1 - 7 0} \\
\text { years }\end{array}$ \\
\hline MNG & 445 & 89 & 24 & 60 & 95 & 158 & 76 & 32 \\
\hline Thyroiditis & 13 & 2.6 & & 3 & 7 & & 3 & \\
\hline PTC & 13 & 2.6 & & 1 & 5 & 3 & 2 & 2 \\
\hline FA & 11 & 2.2 & 1 & 3 & 4 & 2 & 1 & \\
\hline HCA & 4 & 0.8 & & 1 & & 3 & & \\
\hline Poorly differentiated carcinoma & 4 & 0.8 & & & & 2 & 1 & 1 \\
\hline Anaplastic carcinoma & 4 & 0.8 & & & & 1 & 1 & 2 \\
\hline MTC & 3 & 0.6 & & & 1 & & 1 & 1 \\
\hline FC & 2 & 0.4 & & 1 & & 1 & & \\
\hline HTT & 1 & 0.2 & & & & 1 & & \\
\hline
\end{tabular}

MNG: Multinodular goiter, PTC: Papillary thyroid carcinoma, FA: Follicular adenoma, HCA: Hurthle cell adenoma, MTC: Medullary carcinoma, FC: Follicular carcinoma, HTT: Hyalinizing trabecular tumor

Figure 1: Papillary thyroid carcinoma (H\&E,10x, top) showing papillary structures with psammoma bodies, (H\&E, 40x, below) showing intranuclear inclusions (thick arrow) and grooves (thin arrow)

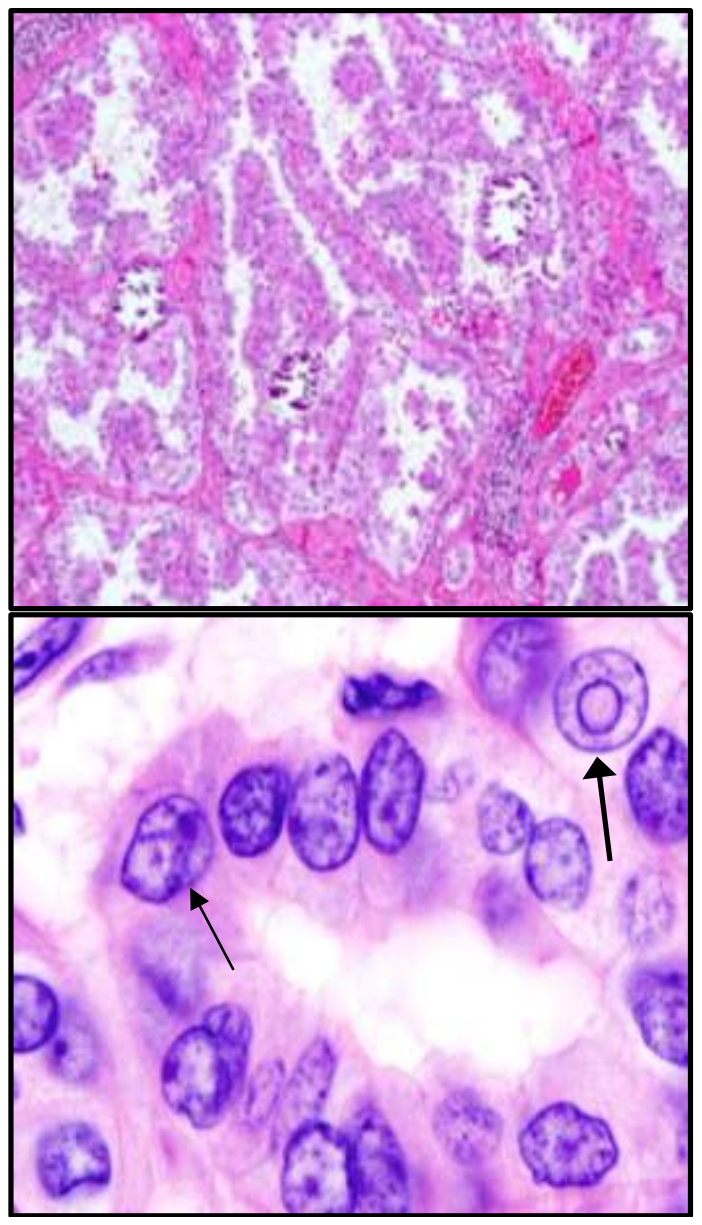

Figure 2: Multinodular goiter (H\&E, 10x, top) showing variable sized thyroid follicles, (H\&E, 40x, below) showing abundant colloid in the follicles

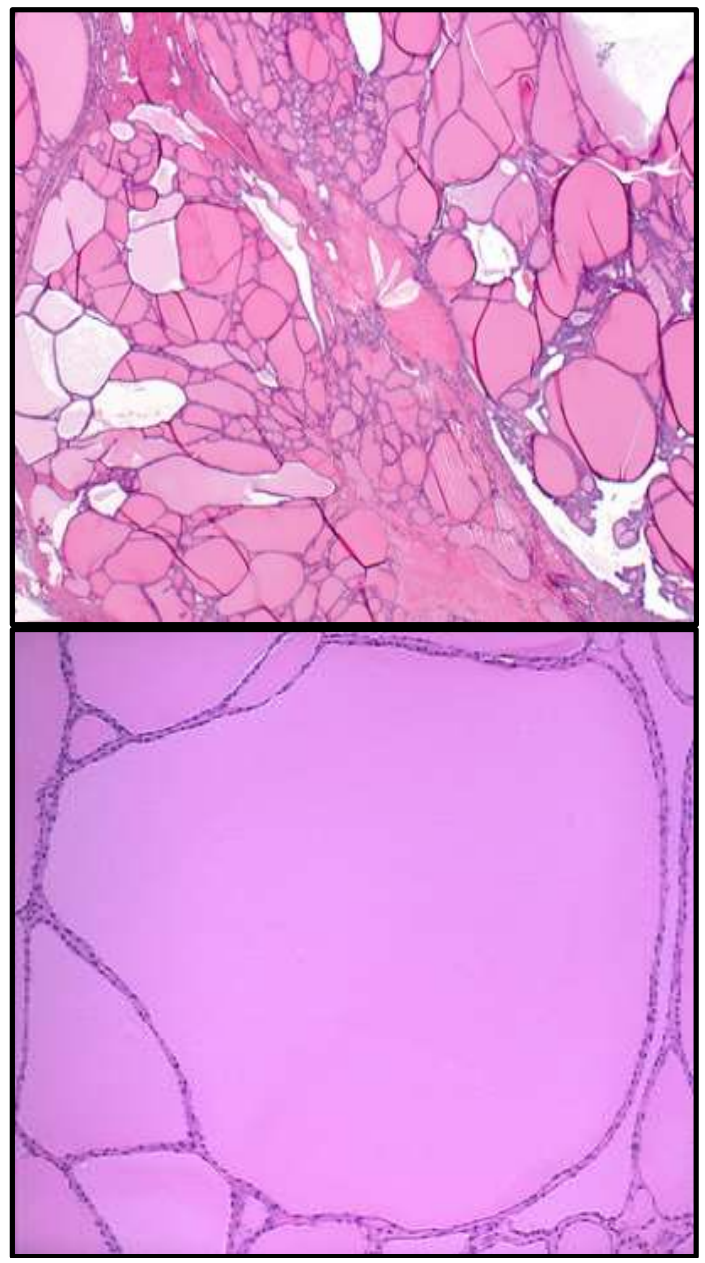




\section{DISCUSSION}

Thyroid diseases are the second most common endocrine disorders after diabetes mellitus worldwide. They are important because they affect all age groups and can be treated both medically and surgically. According to medical facts declared by WHO, $7 \%$ of the world population presented with clinically enlarged thyroid gland and majority of the patients were from developing countries. The most common cause of thyroid enlargement is iodine deficiency which is very common in the northern areas of Pakistan.

According to this study, non-neoplastic lesions of thyroid $(94.80 \%)$ were far more in number than the neoplastic lesions $(5.20 \%)$. This was consistent with previous national and international studies done by Ghafoor A et $a l^{11}$ and joseph E et al ${ }^{12}$ respectively. The frequency of multinodular goiter in this study was $89 \%$ which was slightly more compared to the percentage shown by an Indian study which gave a value of $74 \% .{ }^{13}$ Thyroiditis was the second most common non neoplastic thyroid lesion after multinodular goiter; this finding was consistent with the study done by Joseph E et al. ${ }^{12}$ Follicular adenomas constituted $2.2 \%$ in our study while a study done in $\mathrm{Al}$ Madina region of Saudi Arabia gave a percentage of 1.7.2 Hurthle cell adenoma comprised of $0.8 \%$ of cases in this study while the value provided by the above mentioned Saudi study was $0.6 \%$. The percentages of both types of adenomas were slightly on the lower side in the Saudi study as compared to ours.

The overall frequency of thyroid malignancies in the current study was $5.20 \%$ which was lower than the figure provided by Qureshi IA et al who gave the overall frequency of $11 \%$ in their research article. ${ }^{14}$ The most frequent thyroid malignancy in this study was papillary carcinoma which was consistent with the studies done by Joseph E et al, ${ }^{11}$ Albasri A et al ${ }^{2}$ and Raheem $\mathrm{N}$ et al ${ }^{15}$ but the study conducted by Qureshi IA et al ${ }^{14}$ presented a lower value of papillary carcinoma (1\%). Poorly differentiated carcinoma which has a worse prognosis than well differentiated thyroid carcinomas but better prognosis than anaplastic carcinoma constituted $0.8 \%$ of malignant lesions which is in concordance with a Japanese study published in year 2018.16 Anaplastic carcinoma constituted a value of $0.8 \%$ in our study, similar figure was shown by a Chinese study data of year $2004-2005$ by Zhao L et al. ${ }^{17}$

When correlation of age with different thyroid pathologies was done, it was found that most of the thyroid diseases occur in the age range of 30-50 years, which was consistent with the conclusion derived from the study done by Salami BA et al. ${ }^{18}$ In this study maximum number of cases occurred in the age range of 41-50 years as was also shown by study done by Joseph $\mathrm{E}$ et al. ${ }^{12}$ Papillary carcinoma in our series occurred mostly in the age range of 31- 60 years which is in concordance with the study done by Zhao Y et al. ${ }^{19}$ Carcinoma of old age in present study was anaplastic carcinoma and 50\% of the patients were in the age range of 61-70 years as was in a study done by Hussain SA et al which gave a mean age of 65 years. ${ }^{20}$

\section{CONCLUSION}

The study concluded that the most frequent cause of thyroid enlargement was multinodular goiter (89\%) occurring mostly in 41-50 years. Thyroid carcinomas collectively constituted $5.20 \%$, with papillary carcinoma as the most frequent malignant neoplasm with maximum number of patients in the age range of 31-40 years while anaplastic carcinoma $(0.8 \%)$ was the diagnosis of old age.

\section{LIMITATIONS}

The declaration of lesion as benign and malignant was solely done on morphological findings and no immunohistochemical stain was applied for the confirmation of diagnosis.

\section{SUGGESTIONS / RECOMMENDATIONS}

Thyroidectomy/lobectomy should be done in all those patients with thyroid scan showing cold nodules to rule out malignancy.

\section{CONFLICT OF INTEREST / DISCLOSURE}

There is no conflict of interest in this study.

\section{ACKNOWLEDGEMENTS}

We would like to acknowledge our pathology residents, Dr. Rehana and Dr. Farwa in helping us retrieving the cases from the archives of department for this study as well as our laboratory staff Mr. Rabnawaz and computer clerk Mr. M Aslam Khan.

\section{REFERENCES}

1. Bensenor IM. Thyroid disorders in Brazil: the contribution of the Brazilian longitudinal Study of Adult Health (ELSA-Brasil). Braz J Med Bjol Res. 2019;52(20):8417-28.

2. Albasri A, Sawaf Z, Hussainy AS, Alhujaily A. Histopathological patterns of thyroid disease in Al- Madinah region of Saudi Arabia. Asian Pac J Cancer Prev. 2014;15(14):5565-70.

3. Khan MA, Khan KH, Shah SA, Mir KA, Khattak M, Shahzad MF. Risk Factors associated with Thyroid Carcinoma in North Pakistan. Asian Pac J Cancer Prev. 2016;17(1):377-80.

4. Khodamoradi F, Ghoncheh M, Mehri A, Hassanipour S, Salehiniya $\mathrm{H}$. Incidence, mortality, and risk factors of thyroid cancer in the world: a review. WCRJ. 2018;5(2):e1093

5. Amin SM, Jawa ZM, Gowon JP, George OF, Gagarawa YA, Eiyeje OL. A 10-year review of thyroid lesion in a tertiary hospital in Abuja, Nigeria. Ann Trop Pathol 2018;9(2):118-20.

6. Bashir K, Sarwar R, Saeed S, Mahjabeen I, Kayani MA. Interaction among susceptibility genotypes of PARP1 SNPs in thyroid carcinoma. PLoS One. 2018;13(9):e0199007

7. Pandi V, Shanker H, Indira V, Kumar KM. Profile of non-neoplastic and neoplastic thyroid lesions by fine needle aspiration cytology and their correlation with histopathology- a one-year prospective study in a teaching hospital. Sch Acad J Bio sci. 2016;4:571-7.

8. Jena A, Patnavk R, Prakash J, Sachan A, Suresh V, Lakshmi AY. Malignancy In solitary thyroid nodule: a clinicoradiopathological evaluation. Indian J Endocrinol Metab. 2015;19(4):498-503. 
9. Saeed MI, Hassan AA, Butt ME, et al. Pattern of thyroid lesions in western region of Saudi Arabia: a retrospective analysis and literature review. J Clin Med Res. 2018;10(2):106-16.

10. Sakr HI, Chute DJ, Nasr C, Sturgis CD. cMYC expression in thyroid follicular cell-derived carcinomas: a role in thyroid tumorigenesis. Diagn Pathol. 2017;12(1):71.

11. Ghafoor A, Sajjad M, Akram M, Khan ZA. Histopathological pattern of enlarged thyroid gland. Gomal J Med Sci. 2015;13:20710 .

12. Joseph E, Varghese A, Matthai A, et al. A study on the Histopathological pattern of thyroid lesions in a tertiary care hospital. Int J Res Med Sci. 2016;4(12):5252-5.

13. Amudhan J, Vijay A, Latha G, Anandan H. Clinicopathological Study on Multinodular Goiter: A Prospective Study. Int J Sci Stud 2017;5(1):83-5.

14. Qureshi IA, Khabaz MN, Baig M, Begum B, Abdelrehaman AS, Hussain MB. Histopathological findings in goiter: A review of 624 thyroidectomies. Neuro Endocrinol Lett. 2015;36(1):48-52.
15. Raheem N, Ahmed SA, Samaila MO. Histopathological pattern of thyroid diseases in Zaria: A10- year review. Niger Postgrad Med J. 2018;25(1):37-42

16. Rosenbaum MW, Gigliotti BJ, Pai SI et al. PD-L1 and IDO1 Are Expressed Poorly Differentiated Thyroid Carcinoma. Endocr Pathol. 2018;29(1):59-67.

17. Zhao L, Pang P, Zang $L$ et al. Features and trend of thyroid cancer in patients with thyroidectomies in Beijing, China between 1994 and 2015: a retrospective study. BMJ Open. 2019;9:e023334.

18. Salami BA, Odusan O, Ebilj HO, Akintola PA. Spectrum and prevalence of thyroid diseases seen at a tertiary health facility in Sagamu, South- West Nigeria. Niger Postgrad Med J. 2016;23(3):137-40.

19. Zhao Y, Cao PL, Zhao H. Clinical and pathologic analysis of 2684 cases of papillary thyroid carcinoma in 8 years. Lin Chung Er Bi Yan Hou Tou Jing Wai Ke Za Zhi. 2019;33(4):371-5.

20. Hussain SA, Subbiah S, Bharathiraja MS. Anaplastic Carcinoma Thyroid - A Review on the Management of this Aggressive Cancer. Gulf J Oncolog. 2018;1(28):37-41. 